\title{
Competitive Effects of Mass Customization
}

\author{
Oksana Loginova*
}

May 17, 2010

\begin{abstract}
Earlier theoretical literature on mass customization maintains that customization reduces product differentiation and intensifies price competition. In contrast, operations management studies argue that customization serves primarily to differentiate a company from its competitors. Interactive involvement of the customer in product design creates an affective relationship with the firm, relaxing price competition. This paper provides a model that incorporates consumer involvement to explain the phenomena described in the operations management literature.

Two firms on the Hotelling line compete for a continuum of consumers with heterogeneous brand preferences. An exogenously given fraction of consumers is potentially interested in customization. Consumer benefits from customization are the rewards from a special shopping experience and the value of product customization (better fitting product); these benefits are higher for consumers located closer to the customizing brand. When a consumer purchases a customized product, he incurs the waiting cost. The firms decide whether to offer customization, then engage in price competition. I show that customization increases the "stickiness" of a consumer to the customizing firm, leading to less intense price competition. As mass customization becomes more efficient (the lead time goes down and/or the sunk costs decrease), customization by one or both firms occurs in equilibrium. I perform comparative statics analysis with respect to the fraction of consumers potentially interested in customization.
\end{abstract}

Keywords: horizontal differentiation, price competition, customization, brand loyalty

JEL codes: D43, L13, C72

*Department of Economics, University of Missouri-Columbia, 118 Professional Building, Columbia, MO 65211-6040, USA. E-mail: loginovao@missouri.edu, phone: +1-573-882-0063, fax: +1-573-882-2697. 


\section{Introduction}

Mass customization is the capability to produce individually tailored goods and services for a relatively large market with near mass production efficiency. ${ }^{1}$ Advances in Internetbased information technologies and improvements in manufacturing flexibility have made customization a reality in many product categories. For example, Dell builds to order notebook and desktop computers; Nike and Adidas allow consumers to create their most preferred athletic pair of shoes; apparel vendor Lands' End offers custom-crafted pants and shirts; Timbuk2 customizes messenger bags and backpacks; MiniUSA.com provides with a "build a new MINI" option where the consumer can construct a MINI Cooper car of his dreams.

Theoretical studies of mass customization draw upon the existing literature in spatial and horizontal product differentiation. ${ }^{2}$ Customization enables firms to take advantage of consumers' desires for ideal varieties, but reduces product differentiation and intensifies price competition (Dewan, Jing, and Seidmann, 2003, Syam, Ruan, and Hess, 2005, Syam and Kumar, 2006, Bernhardt, Liu, and Serfes, 2007, Mendelson and Parlaktürk, 2008a, 2008b, Loginova and Wang, forthcoming). Indeed, if two or more firms offer a consumer the product that completely matches the consumer's tastes, then competition leads to marginal cost pricing.

Mass customization differs from the strategy of offering as many variants as possible. For true customization to take place, the customer must be involved in specifying the characteristics of his ideal product during the product design, fabrication, and assembly. ${ }^{3}$ This important aspect of customization has never received direct attention in the theoretical literature. Operations management and information system researchers, on the other hand, have extensively investigated the economic implications of consumer co-design activities. They argue that customization serves primarily to differentiate a company from its competitors. The interactive involvement of the customer in the product design process creates a stronger affective relationship with the firm that subsequently leads to firm loyalty. High loyalty, in turn, relaxes price-based competition

\footnotetext{
${ }^{1}$ The concept of mass customization was coined by Stan Davis in his book Future Perfect (1987), then popularized by Pine (1993). For examples and implementation, see Piller, Moeslein, and Stotko (2004) and the case studies cited in Moser and Piller (2006).

${ }^{2}$ The study of horizontal differentiation dates back to Hotelling (1929), and was extended by Lancaster (1966, 1979) and Salop (1979).

${ }^{3}$ This type of customization is sometimes referred to as collaborative customization, a term introduced by Gilmore and Pine in The Four Faces of Mass Customization (1997). The other three "faces" of customization are adaptive (standard products can be altered by customers during use), cosmetic (standard products are packaged specially for each consumer), and transparent (products are adapted for individual needs). The term "mass customization" is most often associated with collaborative customization.
} 
(Gommans, Krishnan, and Scheffold, 2001, Broekhuizen and Alsem, 2002, Grewal, Iyer, Krishnan, and Sharma, 2003, Arora et al., 2008), which is incompatible with the above theory.

The present paper provides a theoretical model that incorporates consumer interactive involvement to explain the phenomena described in the operations management literature.

\section{Overview of the Model and Results}

I adopt the standard Hotelling model with two firms competing for a continuum of consumers. Consumers are heterogenous in two dimensions. First, each consumer is identified by a point on the unit interval that represents his brand preferences. Second, consumers differ in their "readiness" for customization. Specifically, I assume that a fraction of consumers never buys customized products for exogenous reasons like privacy, lack of computer literacy, or general resistance to change. The rest of consumers are potentially interested in customization.

If a firm chooses to offer customization, it must incur sunk costs associated with migrating a mass-manufacturing system to a build-to-order system (Broekhuizen and Alsem, 2002). I also account for non-zero lead time. When a consumer purchases a customized product, he/she suffers the cost of waiting for the product to be assembled and delivered ( $\mathrm{Tu}$, Vonderembse, and Ragu-Nathan, 2001, Zipkin, 2001).

I assume a positive relationship between consumers' benefits from customization and their valuations of the brand. That is, consumers located "closer" to the brand gain more from customization. This central assumption finds strong support in the operations management literature. Customization benefits are the rewards from a special shopping experience such as satisfaction with the fulfilment of a co-design task (Piller and Müller, 2004, Franke and Piller, 2004) and the value of product customization (i.e., the increment of utility a consumer gains from a product that fits better to his needs than the best standard product available). The rewards from an enjoyable shopping experience are, obviously, higher for consumers who are dedicated to the customizing firm. Also, consumers who favor a certain brand possess more knowledge of this brand. Knowledgeable consumers can more easily transfer their needs into appropriate characteristics of the brand than less knowledgeable ones, and the products they co-design better match their preferences (Jiang, 2004, Piller, Schubert, Koch, and Möslein, 2005). As a result, for these consumers the value of product customization is higher than for consumers located "father away" from the brand.

The timeline of the game is as follows. First, the firms simultaneously decide whether 
to offer customization. ${ }^{4}$ After customization decisions are made, the firms engage in price competition. I assume that a customizing firm is restricted to uniform pricing. ${ }^{5}$ Consumers decide which products to purchase, and the profits are realized.

I show that customization increases the "stickiness" of a consumer to the customizing firm (that is, generates consumer loyalty), leading to less intense price competition. As mass customization becomes more efficient - the lead time goes down and/or the sunk costs decrease, customization by one or both firms occurs in equilibrium.

I perform comparative statics analysis with respect to the level of consumer readiness for customization. Basic intuition suggests that as the fraction of consumers interested in customization increases, customization becomes more likely. I show that in the case of low sunk costs, indeed, the equilibrium changes from customization by one firm to customization by both firms. In contrast, when the sunk costs are high, the equilibrium changes from customization by one firm to no customization.

Prices are affected by the level of consumer readiness for customization only in the case of one customizing firm. I show that the equilibrium prices for standard and custom goods, actually, go down as the fraction of consumers who never buy customized products declines. This is because the presence of such consumers creates a degree of separation between customized and standard products.

\section{Literature Review}

I will briefly summarize earlier theoretical papers on mass customization competition and contrast them with the present study. Next, I will relate my model of customization to advertising with differentiated products literature.

Consumers in Xia and Rajagopalan (2009), like in this paper, are heterogeneous in preferences for the two firms (brands). The firms decide which type of products, standard or customized, to offer and then a standard product firm chooses the product variety and a custom product firm chooses the lead time. Customization eliminates the loss in utility from getting a standard product that does not meet a consumer's needs exactly. Unlike the present study, Xia and Rajagopalan (2009) do not model the rewards and drawbacks of the consumer's active involvement in product configuration process (enjoyable shopping experience and co-design risks). The authors develop an index that

\footnotetext{
${ }^{4}$ I do not allow the firms to offer customized products in addition to their standard products. The role of standard products in customization competition are studied in Dewan, Jing, and Seidmann (2003) and Syam and Kumar (2006).

${ }^{5}$ Obviously, the idea of setting a different price for each variant of a customized product is very appealing. While some firms do engage in price customization (e.g., Dell and Ford), many firms practice uniform pricing. For example, Lands' End charges $\$ 74$ for a pair of jeans regardless of the options chosen; Timbuk2's price is not linked to color and fabric selections.
} 
signifies the relative attractiveness of standardization and customization. They also identify the strategic roles of product variety and lead time.

Other papers that consider duopoly price competition in which the firms choose whether to customize their products assume consumer heterogeneity in product - not brand - preferences. The firms' standard products are located at the end points of the unit interval representing the product space. ${ }^{6}$ Customization reduces (Mendelson and Parlaktürk, 2008b, Syam and Kumar, 2006) or eliminates (Syam, Ruan, and Hess, 2005, Loginova and Wang, forthcoming) a consumer's disutility of misfit - the distance from the consumer's ideal product to the firm's standard product. It follows that customization by one or both firms reduces product differentiation and intensifies price competition. This is diametrically opposite to the present study that shows that customization softens price competition. The difference in the findings can be traced to the differences in the underlying assumptions on the standard product offerings. The above papers assume that initially (before the customization choices are made) each firm produces only one standard product that is maximally differentiated from its rival's standard product. In the present model each firm produces a number of standard products to target consumers of different tastes, and consumers can find a reasonably well fitting product among them. That is, a consumer's disutilities of misfit at the two firms are negatively correlated in the aforementioned papers, but uncorrelated in my model.

The following studies do not allow firms to choose between mass production and customization, focusing instead on technological aspects of flexible manufacturing. Mendelson and Parlaktürk (2008b) consider a traditional firm and a customizing firm. They model replenishment and inventory costs for the traditional firm and assume limited capacity for the customizing firm. In Bernhardt, Liu, and Serfes (2007) two customizing firms acquire information about each individual consumer to match his needs as much as they can. Given investments in information acquisition, the firms then compete in prices. The authors show that in equilibrium the firms make asymmetric investments in order to reduce price competition. In their extension a "brand name" dimension is added. When consumers differ enough on this dimension, then both firms make extensive investments in information acquisition technology. Dewan, Jing, and Seidmann (2003) consider two firms that choose their customization scopes simultaneously, sequentially, and in an incumbent plus entrant situation. They show that an early adopter may be able to keep out potential competitors by choosing its customization scope strategically.

The present study is broadly related to advertising and product differentiation lit-

\footnotetext{
${ }^{6}$ In Syam, Ruan, and Hess (2005) the product space is two-dimensional.
} 
erature. Of the two types of advertising, informative and persuasive, customization has much in common with the latter. ${ }^{7}$ In the context of the Hotelling model, von der Fehr and Stevik (1998) distinguish between three types of persuasive advertising. The first type enhances the value of a product in the eyes of consumers, the second type shifts the distribution of consumers in the direction of the firm's product, and the third type increases perceived product differences. Customization in my model, thus, combines the effects of both the first and the third types of persuasive advertising. The main finding of Von der Fehr and Stevik (1998) is that a positive relationship between the degree of (inherent) product substitutability and equilibrium levels of advertising is consistent only with the advertising that increases perceived product differences.

Despite the similarities between customization and persuasive advertising, my model does not have a close equivalent in advertising literature. Bloch and Manceau (1999) and Tremblay and Polasky (2002) use the Hotelling line, but consider the second (in Von der Fehr and Stevik's terms) type of persuasive advertising. Johnson and Myatt (2006) allow for demand shifts (the first type) and rotations (the third type), but analyze the monopoly supply of a single product. They show that when consumers' valuations are relatively homogenous, the monopolist will choose to serve a large fraction of potential consumers. When consumers are heterogenous, the monopolist will restrict sales to a relatively small "niche" of consumers.

The rest of the paper is organized as follows. In the next section I introduce the model. In Section 3 the pricing stage is analyzed. In Section 4 I study the firms' equilibrium customization choices. Concluding remarks are provided in Section 5. Proofs of all propositions are relegated to the Appendix.

\section{The Model}

Two symmetric firms, A and B, compete for a continuum of heterogeneous consumers with a total mass of one. Firm A produces brand A and firm B produces brand B. If a firm chooses to offer customization, it must incur sunk costs $K \geq 0$ associated with migrating a mass-manufacturing system to a build-to-order system. In the spirit of mass customization's postulate of achieving near mass production efficiency, I assume that both standard and customized products are produced at the same constant marginal costs. I normalize the marginal costs to zero.

\footnotetext{
${ }^{7}$ For informative advertising with differentiated products, see Grossman and Shapiro (1984), Meurer and Stahl (1994), and Villas-Boas (2004).
} 
Consumers are in the market to purchase at most one unit of the product. They are heterogeneous in two dimensions. First, each consumer is identified by a point $x$ in the unit interval $[0,1]$ that represents his relative preference for brand $\mathrm{A}$ versus brand B. To keep the model tractable, I assume that consumers are uniformly distributed along this dimension. Second, independent of $x$, consumers differ in their levels of readiness for customization. Specifically, I assume that fraction $1-\alpha$ of consumers never buy customized products for exogenous reasons like privacy, lack of computer literacy, or general resistance to change. The rest of consumers are potentially interested in customization. For the ease of exposition I will refer to the fraction $1-\alpha$ as traditional consumers and to the fraction $\alpha$ as tech-savvy consumers.

Suppose firm A (firm B) does not offer customization, and sets price $p_{A}\left(p_{B}\right)$ for its standard products. For the consumer at location $x$, the payoff from purchasing a standard product of firm $\mathrm{A}$ is

$$
v-t x-p_{A}
$$

His payoff from purchasing a standard product of firm B is

$$
v-t(1-x)-p_{B}
$$

Parameter $t$ represents the intensity of the consumer's relative preference for brand A versus brand $\mathrm{B}$.

Suppose firm A (firm B) offers customization. Let $\bar{p}_{A}\left(\bar{p}_{B}\right)$ denote the price charged by the firm. (I use the bar to distinguish prices for customized goods from prices for standard goods.) For the consumer at location $x$, the payoff from purchasing a customized product of firm $\mathrm{A}$ is

$$
(1+\Delta)(v-t x)-w-\bar{p}_{A},
$$

where $\Delta>0$ and $w$ is the consumer's cost of waiting for the product to be assembled and delivered. Similarly, his payoff from purchasing a customized product of firm B is

$$
(1+\Delta)(v-t(1-x))-w-\bar{p}_{B}
$$

It follows from (1) and (3), (2) and (4) that the consumer's benefits from customization are

$$
\Delta(v-t x)
$$


if he purchases from firm A,

$$
\Delta(v-t(1-x))
$$

if he purchases from firm B. I believe that the positive relationship between the consumer's valuation of a given brand and his benefits from customization is the most realistic assumption.

In support of this, let me reiterate some parts of the introduction. Customization benefits for consumers are two-fold:

(a) the rewards from a special shopping experience and satisfaction with the fulfilment of a co-design task,

(b) the increment of utility a consumer gains from a product that fits better to his needs than the best standard product available.

The rewards from an enjoyable shopping experience (a) are, obviously, higher for consumers who are dedicated to the customizing firm. The same applies to (b). Indeed, consumers who favor a certain brand would, in general, possess more knowledge of this brand. Knowledgeable consumers can more easily transfer their needs into appropriate characteristics of the brand than less knowledgeable ones, thus the products they co-design better match their preferences.

Since the focus of this paper is on strategic effects of customization rather than customization technology, $\Delta$ and $w$ are treated as exogenous parameters. In reality firms have some control over these variables. They can reduce $w$, for example, by expediting production process and shipping by air. They can increase $\Delta$ by acquiring technologies that foster joint creativity during product design, or reduce the difficulty of transferring customer needs into a concrete product specification.

The game unfolds in two stages. The first stage is the customization stage, in which the firms simultaneously decide to offer either standard or customized products. These decisions become observable after they are made. In the second stage the firms simultaneously choose prices. Consumers subsequently decide which products to purchase, and the firms' profits are realized. The equilibrium concept employed is subgame perfect Nash equilibrium.

\section{Analysis of the Pricing Stage}

In this section I investigate the firms' pricing decisions, taking as given their choices in the first stage of the game. There are four subgames to consider, corresponding to 
the following scenarios: both firms offer standard products; firm A offers customization and firm B produces standard products; firm A produces standard products and firm B offers customization; and both firms offer customization. I denote these subgames by "SS," "CS," "SC," and "CC," where "S" and "C" stand for offering standard and customized products, respectively.

In subsequent analysis the following constraints will be placed on parameters $v, t$, $w, \Delta$ and $\alpha$. First, I assume that the benefits from customization exceed the waiting costs at the aggregate level, but not uniformly. Algebraically,

$$
\int_{0}^{1} \Delta(v-t x) \mathrm{d} x>w
$$

and

$$
\Delta(v-t)<w .
$$

The latter inequality simply means that $\Delta(v-t x)>w$ fails to hold for consumers located further away from the customizing firm. The two inequalities can be combined into one constraint:

$$
\Delta(v-t)<w<\Delta\left(v-\frac{t}{2}\right)
$$

Second, I assume competitive environment. There is enough interest in customization on the part of consumers, i.e., $\alpha$ is not too low. Also, $v$ is sufficiently high so that in equilibrium all consumers buy a product from one of the two firms, with the exception of $1-\alpha$ consumers in subgame CC. The details are provided in Appendix.

These parameter constraints seem reasonable; they will keep the analysis of the model focused and the results tractable.

Subgames SS and CC are straightforward. When both firms offer standard products, the equilibrium prices and profits are as in the standard Hotelling model. That is,

$$
p_{A}^{S S}=p_{B}^{S S}=t \quad \text { and } \quad \Pi_{A}^{S S}=\Pi_{B}^{S S}=\frac{t}{2} .
$$

Higher values of parameter $t$ imply stronger brand preferences, hence less intense price competition.

When both firms offer customization, the equilibrium prices and profits are given by

$$
\bar{p}_{A}^{C C}=\bar{p}_{B}^{C C}=(1+\Delta) t \quad \text { and } \quad \Pi_{A}^{C C}=\Pi_{B}^{C C}=\frac{\alpha(1+\Delta) t}{2} .
$$

Customization increases consumer stickiness to the customizing firms, which softens price competition. The profits of the firms may or may not be higher than those in 


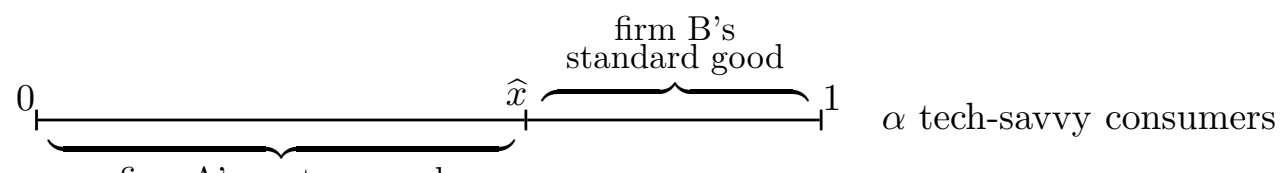

firm A's custom good

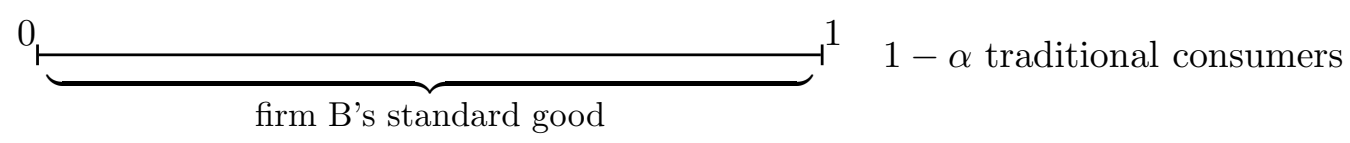

Figure 1: Market shares in subgame CS

subgame SS, however, as fraction $1-\alpha$ drops out from the pool of consumers.

Subgames CS and SC lead to symmetric results. Thus, it suffices to study one of them, subgame CS. When firm A customizes and firm B offers standard products, the payoffs to consumers are given by (2) and (3). Traditional consumers of mass $1-\alpha$ will purchase from firm B. Tech-savvy consumers from interval $[0, \widehat{x}]$ will purchase from firm A, whereas those with $x \in(\widehat{x}, 1]$ will purchase from firm $\mathrm{B}$. The marginal type $\widehat{x}$ is given by

$$
\widehat{x}\left(\bar{p}_{A}, p_{B}\right)=\frac{\Delta v-w+t-\bar{p}_{A}+p_{B}}{(2+\Delta) t} .
$$

These optimal decisions of consumers are illustrated in Figure 1.

The firms simultaneously choose $\bar{p}_{A}$ and $p_{B}$ to maximize their profits,

$$
\Pi_{A}\left(\bar{p}_{A}, p_{B}\right)=\alpha \widehat{x}\left(\bar{p}_{A}, p_{B}\right) \bar{p}_{A}
$$

and

$$
\Pi_{B}\left(\bar{p}_{A}, p_{B}\right)=\alpha\left(1-\widehat{x}\left(\bar{p}_{A}, p_{B}\right)\right) p_{B}+(1-\alpha) p_{B} .
$$

Proposition 1 (Equilibrium prices and profits in subgame CS). Suppose firm A customizes and firm $B$ offers standard products. The equilibrium prices and profits are

$$
\left\{\begin{array}{l}
\bar{p}_{A}^{C S}=\frac{(2+\Delta) t}{3 \alpha}+\frac{\Delta v-w+t}{3} \\
p_{B}^{C S}=\frac{2(2+\Delta) t}{3 \alpha}-\frac{\Delta v-w+t}{3}
\end{array}\right.
$$

and

$$
\left\{\begin{array}{l}
\Pi_{A}^{C S}=\frac{\alpha}{(2+\Delta) t}\left(\frac{(2+\Delta) t}{3 \alpha}+\frac{\Delta v-w+t}{3}\right)^{2} \\
\Pi_{B}^{C S}=\frac{\alpha}{(2+\Delta) t}\left(\frac{2(2+\Delta) t}{3 \alpha}-\frac{\Delta v-w+t}{3}\right)^{2}
\end{array}\right.
$$




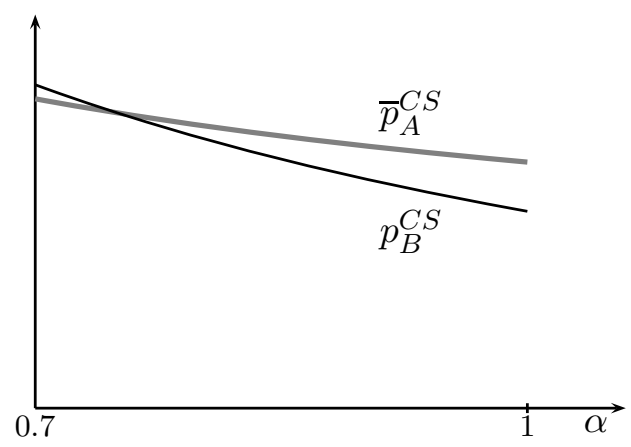

(a)

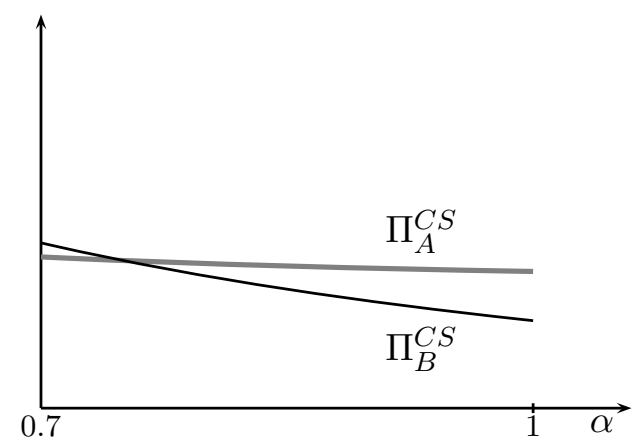

(b)

Figure 2: Equilibrium (a) prices and (b) profits in subgame CS, $w=\Delta(v-t)$

Tech-savvy consumers with $x \leq \widehat{x}^{C S}$ will purchase from firm A, the rest will purchase from firm $B$, where

$$
\widehat{x}^{C S}=\frac{1}{(2+\Delta) t}\left(\frac{(2+\Delta) t}{3 \alpha}+\frac{\Delta v-w+t}{3}\right) .
$$

In the spirit of parameter constraint (5), I will focus on the two boundary cases, $w=\Delta(v-t)$ and $w=\Delta(v-t / 2)$, and then perform comparative statics analysis with respect to parameter $\alpha$. The smaller is $w$, the more time efficient is production of customized goods. Thus, I will refer to $w=\Delta(v-t)$ as the case of highly efficient customization technology and to $w=\Delta(v-t / 2)$ as marginally efficient.

When $w=\Delta(v-t)$, the expressions in Proposition 1 become

$$
\left\{\begin{array} { l } 
{ \overline { p } _ { A } ^ { C S } ( \alpha ) = ( \frac { 2 + \Delta } { 3 \alpha } + \frac { 1 + \Delta } { 3 } ) t } \\
{ p _ { B } ^ { C S } ( \alpha ) = ( \frac { 2 ( 2 + \Delta ) } { 3 \alpha } - \frac { 1 + \Delta } { 3 } ) t }
\end{array} \quad \text { and } \quad \left\{\begin{array}{l}
\Pi_{A}^{C S}(\alpha)=\frac{\alpha}{2+\Delta}\left(\frac{2+\Delta}{3 \alpha}+\frac{1+\Delta}{3}\right)^{2} t \\
\Pi_{B}^{C S}(\alpha)=\frac{\alpha}{2+\Delta}\left(\frac{2(2+\Delta)}{3 \alpha}-\frac{1+\Delta}{3}\right)^{2} t
\end{array}\right.\right.
$$

As we see from Figure 2(a), the equilibrium prices are decreasing functions of $\alpha$. The intuition behind this result is as follows. When one firm (firm A) customizes and the other firm (firm B) offers standard products, the firms compete with each other only for tech-savvy consumers of mass $\alpha$. Traditional consumers of mass $1-\alpha$ all purchase from the non-customizing firm. The smaller is the number of traditional consumers (or, equivalently, the higher is the number of tech-savvy ones), the more aggressively firm $\mathrm{B}$ competes with firm A for tech-savvy consumers. Hence, the equilibrium prices $\bar{p}_{A}^{C S}$ and $p_{B}^{C S}$ decrease in parameter $\alpha$. 


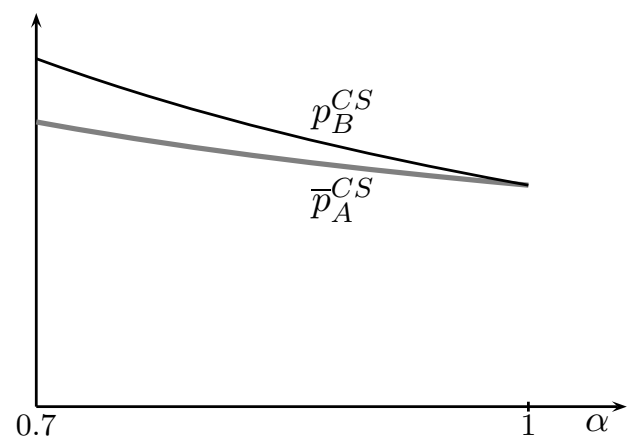

(a)

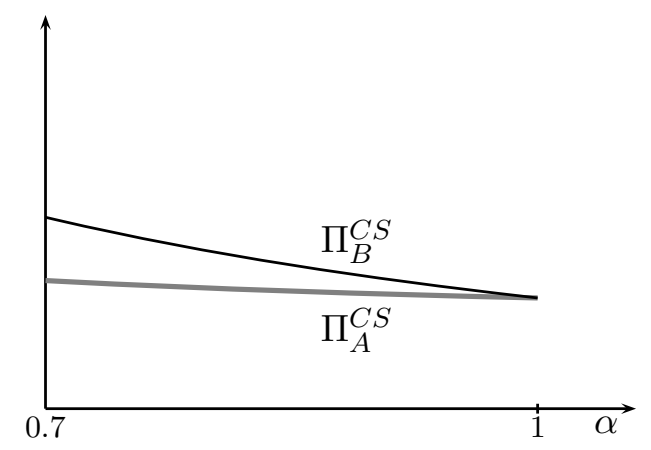

(b)

Figure 3: Equilibrium (a) prices and (b) profits in subgame CS, $w=\Delta(v-t / 2)$

How does $\alpha$ affect the firms' market shares? In equilibrium firm A serves

$$
\alpha \widehat{x}^{C S}=\frac{1}{3}+\frac{\alpha(1+\Delta)}{3(2+\Delta)}
$$

customers, and firm B serves the rest. It is easy to see that the market share of the customizing firm increases in $\alpha$, immediately implying that firm B's market share decreases in $\alpha$.

Figure 2(b) depicts the firms' equilibrium profits. The higher is the fraction of consumers potentially interested in customization, $\alpha$, the lower is the profit of the noncustomizing firm B. This result conforms with economic intuition. Interestingly, the profit of the customizing firm A also decreases in $\alpha$. The reason is that firm A's market share increases is $\alpha$ at a slower rate than $\bar{p}_{A}^{C S}$ decreases.

Finally, observe that firm A's equilibrium price and profit are higher than those of firm $\mathrm{B}$, provided that $\alpha$ is not too low.

We next consider the case of marginally efficient customization technology, $w=$ $\Delta(v-t / 2)$. The firms' equilibrium prices and profits are

$$
\left\{\begin{array} { l } 
{ \overline { p } _ { A } ^ { C S } ( \alpha ) = ( 2 + \Delta ) ( \frac { 1 } { 3 \alpha } + \frac { 1 } { 6 } ) t } \\
{ p _ { B } ^ { C S } ( \alpha ) = ( 2 + \Delta ) ( \frac { 2 } { 3 \alpha } - \frac { 1 } { 6 } ) t }
\end{array} \quad \text { and } \quad \left\{\begin{array}{l}
\Pi_{A}^{C S}(\alpha)=\alpha(2+\Delta)\left(\frac{1}{3 \alpha}+\frac{1}{6}\right)^{2} t \\
\Pi_{B}^{C S}(\alpha)=\alpha(2+\Delta)\left(\frac{2}{3 \alpha}-\frac{1}{6}\right)^{2} t
\end{array}\right.\right.
$$

As can be seen from Figure 3, all four functions are decreasing in $\alpha$. The intuition is the same as in the case $w=\Delta(v-t / 2)$.

In contrast to Figure 2, in Figure 3 the equilibrium price and profit of the customizing firm are lower than those of the non-customizing firm. Specifically, at $\alpha=1$ the equilibrium prices and profits of the two firms are equal. When $\alpha<1$, firm $\mathrm{B}$ sets 
higher price and earns higher profit than firm A. This result is intuitive, as the case $w=\Delta(v-t / 2)$ corresponds to customization technology that, in terms of efficiency, is comparable to standard products.

Having derived the profit functions for the pricing stage, we move one step back to study the customization stage.

\section{Equilibrium Customization Choices}

In the customization stage the firms simultaneously decide whether to customize their products. The strategic form of this game is given by

\begin{tabular}{cc|c|c} 
& & \multicolumn{2}{|c}{ Firm B } \\
Firm A & $\mathrm{S}$ & $\mathrm{C}$ \\
\cline { 2 - 4 } & $\mathrm{S}$ & $\Pi_{A}^{S S}, \Pi_{B}^{S S}$ & $\Pi_{A}^{S C}, \Pi_{B}^{S C}-K$ \\
\hline $\mathrm{C}$ & $\Pi_{A}^{C S}-K, \Pi_{B}^{C S}$ & $\Pi_{A}^{C C}-K, \Pi_{B}^{C C}-K$
\end{tabular}

where $K$ is the fixed cost of customization. Let

$$
g^{S} \equiv \Pi_{A}^{C S}-\Pi_{A}^{S S}=\Pi_{B}^{S C}-\Pi_{B}^{S S}
$$

denote firm A's (firm B's) change in gross profit in the first column (the first row) and

$$
g^{C} \equiv \Pi_{A}^{C C}-\Pi_{A}^{S C}=\Pi_{B}^{C C}-\Pi_{B}^{C S}
$$

denote firm A's (firm B's) change in gross profit in the second column (the second row). These changes represent one firm's relative gains from customization conditional on the choice of the other firm.

Lemma 1 (Relative gains from customization). At each point of the parameter space the relative gains from customization are higher when the other firm offers standard products than when it customizes, $g^{S} \geq g^{C}$. Moreover, $g^{S}>0$ and decreases in $\alpha$, whereas $g^{C}$ increases in $\alpha$.

In subgame CS, both firms' equilibrium profits are decreasing functions of $\alpha$ (Figures 2 (b) and 3(b)). Since $\Pi_{A}^{S S}=t / 2$ is not affected by $\alpha$, it follows immediately that $g^{S}=\Pi_{A}^{C S}-\Pi_{A}^{S S}$ decreases in $\alpha$. Next, $g^{C}=\Pi_{B}^{C C}-\Pi_{B}^{C S}$ increases in $\alpha$, because the first term, $\alpha(1+\Delta) t / 2$, increases in $\alpha$, and the second term decreases.

The result that $g^{S} \geq g^{C}$ is intuitive. The firm that undertakes customization gains 


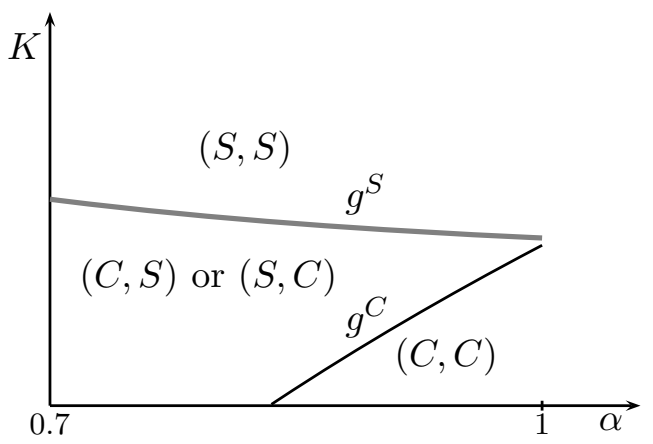

(a)

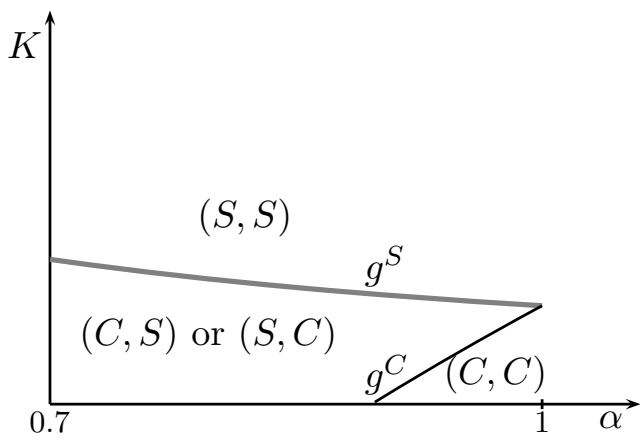

(b)

Figure 4: Equilibrium customization choices, (a) $w=\Delta(v-t)$ and (b) $w=\Delta(v-t / 2)$

more when the other firm is not customizing because the presence of traditional consumers softens the price competition between the two firms in subgames CS and SC.

Lemma 1 has implications for the firms' equilibrium choices, which are summarized in the following proposition.

Proposition 2 (Equilibrium customization choices). The following holds for the firms' equilibrium customization choices.

$\left.\begin{array}{l}(\mathrm{C}, \mathrm{S}) \text { or }(\mathrm{S}, \mathrm{C}) \\ (\mathrm{C}, \mathrm{C})\end{array}\right\}$ is a Nash equilibrium if $\left\{\begin{array}{l}K \geq g^{S} \\ K \in\left[g^{C}, g^{S}\right] \\ K \leq g^{C}\end{array}\right.$

where

$$
g^{S}=\frac{\alpha}{(2+\Delta) t}\left(\frac{(2+\Delta) t}{3 \alpha}+\frac{\Delta v-w+t}{3}\right)^{2}-\frac{t}{2}
$$

and

$$
g^{C}=\frac{\alpha(1+\Delta) t}{2}-\frac{\alpha}{(2+\Delta) t}\left(\frac{2(2+\Delta) t}{3 \alpha}-\frac{\Delta v-w+t}{3}\right)^{2} .
$$

Figure 4(a) plots the relative gains from customization as functions of $\alpha$ for the case of highly efficient customization technology, and Figure 4(b) - for the case of marginally efficient technology.

Proposition 2 together with the graphical properties of functions $g^{S}$ and $g^{C}$ imply the following.

- As customization technology becomes more efficient, the equilibrium changes in the direction from $(\mathrm{S}, \mathrm{S})$ to $(\mathrm{C}, \mathrm{S}) /(\mathrm{S}, \mathrm{C})$ to $(\mathrm{C}, \mathrm{C})$. 
- As the fixed cost of customization $K$ increases, the equilibrium changes in the direction from $(\mathrm{C}, \mathrm{C})$ to $(\mathrm{C}, \mathrm{S}) /(\mathrm{S}, \mathrm{C})$ to $(\mathrm{S}, \mathrm{S})$.

- For small values of $K$, at least one firm customizes in equilibrium. As the fraction of consumers potentially interested in customization increases, the equilibrium changes from $(\mathrm{C}, \mathrm{S}) /(\mathrm{S}, \mathrm{C})$ to $(\mathrm{C}, \mathrm{C})$.

- For large (but not prohibitively large) values of $K$, only one of the firms customizes in equilibrium. Interestingly, as the fraction of consumers interested in customization increases, the equilibrium changes from $(\mathrm{C}, \mathrm{S}) /(\mathrm{S}, \mathrm{C})$ to $(\mathrm{S}, \mathrm{S})$.

The first conclusion is intuitive. The less consumers have to wait for a customized product to be produced and delivered, the more they are willing to pay for customization. As a result, the firms' relative gains from customization shift upward as $w$ decreases: $g^{S}$ and $g^{C}$ are higher in Figure 3(a) than in 3(b). This shift explains the pattern (S,S) to $(\mathrm{C}, \mathrm{S}) /(\mathrm{S}, \mathrm{C})$ to $(\mathrm{C}, \mathrm{C})$.

What drives the second conclusion is the fact that $g^{S} \geq g^{C}$. If $K$ is such that a firm has incentives to customize given that the other firm customizes, then it would also want to customize given that the other firm offers standard products. Accordingly, the equilibrium changes from $(\mathrm{C}, \mathrm{C})$ to $(\mathrm{C}, \mathrm{S}) /(\mathrm{S}, \mathrm{C})$ to $(\mathrm{S}, \mathrm{S})$ as the fixed cost of customization increases.

How does $\alpha$ affect the equilibrium customization choices? Economic intuition suggests that as the number of consumers interested in customization increases, customization becomes more likely. This intuition is confirmed for small values of $K$ (the third conclusion). However, when $K$ is large the equilibrium changes from $(\mathrm{C}, \mathrm{S}) /(\mathrm{S}, \mathrm{C})$ to (S,S) as $\alpha$ approaches 1 (the fourth conclusion). What drives this intriguing result is the fact that $g^{S}$ is a decreasing function of $\alpha$.

\section{Concluding Remarks}

In this section I will summarize the important features of the paper that distinguish it from other papers in customization literature.

The present paper is the first one to model consumer interactive involvement in product design. This aspect of mass customization has never been the focus of the theoretical literature on customization. I incorporated benefits and drawbacks of customer co-design activities - enjoyable shopping experience, difficulties in transferring individual needs into appropriate product characteristics, waiting costs - into customization competition. 
The paper also views the standard product offerings in a manner different than most of earlier theoretical literature. Each firm initially produces a range of standard products, so every consumer can find a reasonably well fitting product to suit his individual needs. The competing firms may end up offering very similar standard products: the differences between Nike's and Adidas' running shoes are far smaller than the differences between running and basketball shoes made by Nike, and the differences between geometries of the $56 \mathrm{~cm}$ frames produced by Specialized and Treck bike manufacturers are smaller than the differences between the $56 \mathrm{~cm}$ and $48 \mathrm{~cm}$ frames made by Treck. At this point, the only distinction in the eye of the consumer is the brand name attached to these products. Therefore in my model, consumer heterogeneity on the Hotelling line is interpreted as variability in preferences for brand, rather than product attributes.

The new modeling ideas were motivated by, and aimed at explaining, the predominant findings in the operations management literature that customization softens price competition, because affective bonds are formed between the firm and its customers as a result of consumer interactive involvement in co-design activities. These findings apparently contradict earlier theoretical literature on customization that maintains that customization reduces product differentiation and intensifies price competition. The importance of the present study is that it provides a theoretical model consistent with the phenomena described in the operations management literature.

Other findings of this paper may also be useful. As mass customization is an emerging business strategy, one might want to know how the level of consumer readiness for customization affects firms' customization choices and prices. I conducted a comparative statics analysis that has revealed a number of interesting results.

\section{Appendix}

Proof of (7). When both firms offer customization, the marginal type $\widehat{x}$ is given by

$$
(1+\Delta)(v-t x)-w-\bar{p}_{A}=(1+\Delta)(v-t(1-x))-w-\bar{p}_{B}
$$

or

$$
\widehat{x}=\frac{(1+\Delta) t-\bar{p}_{A}+\bar{p}_{B}}{2(1+\Delta) t} .
$$

The firms simultaneously choose $\bar{p}_{A}$ and $\bar{p}_{B}$ to maximize their profits,

$$
\Pi_{A}=\alpha \widehat{x} \bar{p}_{A}=\frac{\alpha\left((1+\Delta) t-\bar{p}_{A}+\bar{p}_{B}\right) \bar{p}_{A}}{2(1+\Delta) t}
$$


and

$$
\Pi_{B}=\alpha(1-\widehat{x}) \bar{p}_{B}=\frac{\alpha\left((1+\Delta) t-\bar{p}_{B}+\bar{p}_{A}\right) \bar{p}_{B}}{2(1+\Delta) t} .
$$

The first-order conditions

$$
\left\{\begin{array}{l}
\frac{\partial \Pi_{A}}{\partial \bar{p}_{A}}=0 \\
\frac{\partial \Pi_{B}}{\partial p_{B}}=0
\end{array}\right.
$$

yield the equilibrium prices and profits in (7).

Proof of Proposition 1. When firm A customizes and firm B offers a standard product, the marginal type $\widehat{x}$ is given by

$$
(1+\Delta)(v-t x)-w-\bar{p}_{A}=v-t(1-x)-p_{B},
$$

or

$$
\widehat{x}=\frac{\Delta v-w+t-\bar{p}_{A}+p_{B}}{(2+\Delta) t} .
$$

The firms simultaneously choose $\bar{p}_{A}$ and $p_{B}$ to maximize their profits,

$$
\Pi_{A}=\alpha \widehat{x} \bar{p}_{A}=\frac{\alpha\left(\Delta v-w+t-\bar{p}_{A}+p_{B}\right) \bar{p}_{A}}{(2+\Delta) t}
$$

and

$$
\begin{aligned}
\Pi_{B} & =\alpha(1-\widehat{x}) p_{B}+(1-\alpha) p_{B}=p_{B}-\alpha \widehat{x} p_{B} \\
& =p_{B}-\frac{\alpha\left(\Delta v-w+t-\bar{p}_{A}+p_{B}\right) p_{B}}{(2+\Delta) t} .
\end{aligned}
$$

The first-order conditions

$$
\left\{\begin{array}{l}
\frac{\partial \Pi_{A}}{\partial \bar{p}_{A}}=\frac{\alpha\left(\Delta v-w+t-2 \bar{p}_{A}+p_{B}\right)}{(2+\Delta) t}=0 \\
\frac{\partial \Pi_{B}}{\partial p_{B}}=1-\frac{\alpha\left(\Delta v-w+t-\bar{p}_{A}+2 p_{B}\right)}{(2+\Delta) t}=0
\end{array}\right.
$$

yield the equilibrium prices

$$
\left\{\begin{array}{l}
\bar{p}_{A}^{C S}=\frac{(2+\Delta) t}{3 \alpha}+\frac{\Delta v-w+t}{3} \\
p_{B}^{C S}=\frac{2(2+\Delta) t}{3 \alpha}-\frac{\Delta v-w+t}{3}
\end{array}\right.
$$

We substitute $\bar{p}_{A}^{C S}$ and $p_{B}^{C S}$ into the firms' profit functions to get the equilibrium profits 
in subgame CS,

$$
\left\{\begin{array}{l}
\Pi_{A}^{C S}=\frac{\alpha}{(2+\Delta) t}\left(\frac{(2+\Delta) t}{3 \alpha}+\frac{\Delta v-w+t}{3}\right)^{2} \\
\Pi_{B}^{C S}=\frac{\alpha}{(2+\Delta) t}\left(\frac{2(2+\Delta) t}{3 \alpha}-\frac{\Delta v-w+t}{3}\right)^{2}
\end{array}\right.
$$

Proof of Lemma 1. The algebraic expressions for $g^{S}$ and $g^{C}$ are given by

$$
g^{S}=\frac{\alpha}{(2+\Delta) t}\left(\frac{(2+\Delta) t}{3 \alpha}+\frac{\Delta v-w+t}{3}\right)^{2}-\frac{t}{2}
$$

and

$$
g^{C}=\frac{\alpha(1+\Delta) t}{2}-\frac{\alpha}{(2+\Delta) t}\left(\frac{2(2+\Delta) t}{3 \alpha}-\frac{\Delta v-w+t}{3}\right)^{2} .
$$

Tedious but straightforward numerical calculations confirm that $g^{S} \geq g^{C}$ at each point of the parameter space (with the constraints specified in the second and third paragraphs of Section 3 in place). Numerical calculations also imply that

$$
\frac{\alpha}{(2+\Delta) t}\left(\frac{(2+\Delta) t}{3 \alpha}+\frac{\Delta v-w+t}{3}\right)^{2}
$$

and

$$
\frac{\alpha}{(2+\Delta) t}\left(\frac{2(2+\Delta) t}{3 \alpha}-\frac{\Delta v-w+t}{3}\right)^{2}
$$

both are decreasing functions of $\alpha$. It immediately follows that $g^{S}$ decreases in $\alpha$ and $g^{C}$ increases in $\alpha$.

Proof of Proposition 2. The results follow immediately from Lemma 1 and the discussion preceding Proposition 2.

\section{References}

[1] Arora, Neeraj, Xavier Dreze, Anindya Ghose, James D. Hess, Raghuram Iyengar, Bing Jing, Yogesh Joshi, V. Kumar, Nicholas Lurie, Scott Neslin, S. Sajeesh, Meng Su, Niladri Syam, Jacquelyn Thomas, and Z. John Zhang, 2008, "Putting One-toone Marketing to Work: Personalization, Customization, and Choice," Marketing Letters, 19(3-4), pp. 305-321.

[2] Bernhardt, Dan, Qihong Liu, and Konstantinos Serfes, 2007, "Product Customization," European Economic Review, 51(6), pp. 1396-1422. 
[3] Bloch, Francis, and Delphine Manceau, 1999, "Persuasive Advertising in Hotelling's model of Product Differentiation", International Journal of Industrial Organization, $17(4)$, pp. 557-574.

[4] Broekhuizen, Thijs Lennart Jaap, and Karel Jan Alsem, 2002, "Success Factors for Mass Customization: A Conceptual Model," Journal of Market-Focused Management, 5(4), pp. 309-330.

[5] Dewan, Rajiv, Bing Jing, and Abraham Seidmann, 2003, "Product Customization and Price Competition on the Internet," Management Science, 49(8), pp. 1055-1070.

[6] Davis, Stan, 1987, Future Perfect, Addison-Wesley, Reading, MA.

[7] Franke, Nikolaus, and Frank Piller, 2004, "Value Creation by Toolkits for User Innovation Design: The Case of Watch Market," Journal of Product Innovation Management, 21(6), pp. 401-415.

[8] Gilmore, James H., and B. Joseph Pine II, 1997, "The Four Faces of Mass Customization," Harvard Business Review, 75(1), pp. 91-101.

[9] Gommans, Marcel, Krish S. Krishnan, and Katrin B. Scheffold, 2001, "From Brand Loyalty to E-Loyalty: A Conceptual Framework," Journal of Economics and Social Research, 3(1), pp. 43-58.

[10] Grewal, Dhruv, Gopalkrishnan R. Iyer, R. Krishnan, and Arun Sharma, 2003, "The Internet and the Price-Value-Loyalty Chain," Journal of Business Research, 56(5), pp. 391-398.

[11] Grossman, Gene M., and Carl Shapiro, 1984, "Informative Advertising with Differentiated Products," Review of Economic Studies, 51(1), pp. 63-81.

[12] Hotelling, Harold, 1929, "Stability in Competition," Economic Journal, 39(153), pp. 41-57.

[13] Jiang, Pingjun, 2004, "The Role of Brand Name in Customization Decisions: A Search vs Experience Perspective," Journal of Product and Brand Management, 13(2), pp. 73-83.

[14] Johnson, Justin P., and David P. Myatt, 2006, "On the Simple Economics of Advertising, Marketing, and Product Design," American Economic Review, 96(3), pp. 756-784. 
[15] Lancaster, Kelvin J., 1966, "A New Approach to Consumer Theory," Journal of Political Economy, 74(2), 132-157.

[16] —, 1979, Variety, Equity and Efficiency, Columbia University Press, New York.

[17] Loginova, Oksana, and X. Henry Wang, forthcoming, "Customization with Vertically Differentiated Products," Journal of Economics and Management Strategy.

[18] Mendelson, Haim, and Ali K. Parlaktürk, 2008a, "Competitive Customization," Manufacturing and Service Operations Management, 10(3), pp. 377-390.

[19] —, 2008b, "Product-Line Competition: Customization vs. Proliferation," Management Science, 54(12), pp. 2039-2053.

[20] Meurer, Michael, and Dale O. Stahl II, 1994, "Informative Advertising and Product Match," International Journal of Industrial Organization, 12(1), pp. 1-19.

[21] Moser, Klaus, and Frank T. Piller, 2006, "The International Mass Customization Case Collection: An Opportunity for Learning from Previous Experiences," International Journal of Mass Customization, 1(4), pp. 403-409.

[22] Piller, Frank T., Kathrin Moeslein, and Christof M. Stotko, 2004, "Does Mass Customization Pay? An Economic Approach to Evaluate Customer Integration," Production Planning and Control, 15(4), pp. 435-444.

[23] Piller, Frank T., and Melanie Müller, 2004, "A New Marketing Approach to Mass Customisation," Interantional Journal of Computer Integrated Manufacuring, 17(7), pp. 583-593.

[24] Piller, Frank, Petra Schubert, Michael Koch, and Kathrin Möslein, 2005, "Overcoming Mass Confusion: Collaborative Customer Co-design in Online Communities," Journal of Computer-Mediated Communication, 10(4), article 8.

[25] Pine, B. Joseph, 1993, Mass Customization: The New Frontier in Business Competition, Harvard Business School Press, Boston, MA.

[26] Salop, Steven C., 1979, "Monopolistic Competition with Outside Goods," Bell Journal of Economics, 10(1), pp. 141-156.

[27] Syam, Niladri B., and Nanda Kumar, 2006, "On Customized Goods, Standard Goods, and Competition," Marketing Science, 25(5), pp. 525-537. 
[28] Syam, Niladri B., Ranran Ruan, and James D. Hess, 2005, "Customized Products: A Competitive Analysis," Marketing Science, 24(4), pp. 569-584.

[29] Tremblay, Victor J., and Stephen Polasky, 2002, "Advertising with Subjective Horizontal and Vertical Product Differentiation," Review of Industrial Organization, 20(3), pp. 253-265.

[30] Tu, Qiang, Mark A. Vonderembse, and T.S. Ragu-Nathan, 2001, "The Impact of Time-Based Manufacturing Practices on Mass Customization and Value to Customer," Journal of Operations Management, 19(2), pp. 201-217.

[31] Villas-Boas, J. Miguel, 2004, "Consumer Learning, Brand Loyalty, and Competition," Marketing Science, 23(1), pp. 134-145.

[32] Von der Fehr, Nils-Henrik M., and Kristin Stevik, 1998, "Persuasive Advertising and Product Differentiation," Southern Economic Journal, 65(1), pp. 113-126.

[33] Xia, Nan, and S. Rajagopalan, 2009, "Standard vs. Customized Products: Variety, Lead Time, and Price Competition," Marketing Science, 28(5), pp. 887-900.

[34] Zipkin, Paul, 2001, "The Limits of Mass Customization," Sloan Management Review, 42(3), pp. 81-87. 